\title{
Uma sociedade fragmentada e fundamentalmente una: La société féodale
} e a sociedade feudal

\author{
Eduardo Henrik Aubert**
}

Um clássico da historiografia, La société féodale levanta ainda hoje polêmica sobre questões elementares, como a definição de seu objeto e o referencial teórico com que dialoga. Neste texto, procuramos encaminhar essas questões, examinando algumas noções centrais que interferem no recorte de objeto da obra e discutindo algumas das referências com que o livro dialoga, sobretudo a sociologia durkheimiana. Palavras-chave: La société féodale - Marc Bloch - Escola dos Annales

A fragmented and essentially cohese society: La sociétéféodale and feudal society A classic of historiography, La société féodale still raises discussion about elementary issues, such as the definition of its object and the theoretical references with which it is related. We attempt to approach these issues by examining some key notions in the definition of the work's object and by discussing some of the references that interfere in the conception of the book, especially Durkeim's sociology.

\footnotetext{
* Artigo recebido em agosto de 2007 e aprovado para publicação em setembro de 2007.

** Doutorando em Histoire et Civilisations na EHESS - Paris e bolsista Capes. E-mail: eh.aubert@hotmail.com.
} 
Keywords: La société feodale - Marc Bloch - École des Annales

\section{Une société morcelée et essentiellement une: La sociétéféodale et la société féodale}

Un classique de l'historiographie, La société féodale continue à créer des polémiques sur des questions élémentaires, comme la définition de son objet et ses références théoriques. Nous essayons de traiter ces questions en examinant quelques notions centrales pour la définition de l'objet de l'œuvre et en discutant quelques références théoriques importantes pour le livre, surtout la sociologie durkheimienne.

Mots-clés: La société féodale - Marc Bloch - École des Annales

"O que foi a 'sociedade feudal'? Eviden-
temente há que ler e reler o admirável
trabalho de Marc Bloch. No entanto, esse
trabalho suscitou tantas e tão fecundas
investigações que a maior parte do que
sugeria há perto de quarenta anos tem de
ser rectificado."

\section{Introdução}

A fortuna crítica de La sociétéféodale, a cujos volume e qualidade referese Duby em nossa epígrafe, já passa hoje dos sessenta e cinco anos. Desde a primeira avaliação emitida pelo amigo Lucien Febvre, em janeiro de 1940, ${ }^{2}$ até hoje, as opiniões têm-se sobreposto, concordando e discordando, em uma história peculiar e particularmente intricada. Em conjunto com a criação de uma memória a respeito de Bloch e dos primeiros anos da revista Annales, no bojo das reviravoltas da historiografia ao longo do século XX, formou-se todo um espectro de posições, debates e preocupações em torno de La société féodale. Não pretendemos, aqui, percorrer esse trajeto, ainda que extrema-

\footnotetext{
${ }^{1}$ Geor ges Duby, “História e sociologia do Ocidente medieval - resultados e pesquisas” [1970], trad., em: , A sociedade cavaleiresca, São Paulo, Martins Fontes, 1989, p. 173.

${ }^{2}$ Lucien Febvre, "Compte-rendu de La societé féodale: la formation des liens de dépendance”, Annales d'histoire économique et sociale, 2, 1940, p. 40-42.
} 
mente interessante em si. ${ }^{3}$ Observemos, de todo modo, como duas questões absolutamente centrais na apreciação de uma obra suscitaram, no caso de $L a$ société féodale, juízos surpreendentemente díspares.

Primeiramente, a circunscrição do objeto. $\mathrm{Na}$ introdução do primeiro volume da obra, Bloch delimitava seu objeto nos seguintes termos: "é a análise e a explicação de uma estrutura social, com suas conexões (liaisons), que aqui se propõe tentar". ${ }^{4}$ A leitura dessa proposição mostrou-se, contudo, bastante mais obscura e duvidosa do que uma enunciação de tal modo breve poderia deixar prever. Daniel Chirot compreendeu esse objeto como sendo a "história de uma grande civilização", 5 sendo que civilização "referia-se ao total dos componentes materiais, psicológicos e estruturais de uma sociedade", ${ }^{6}$ posição esposada por Ulrich Raulff. ${ }^{7}$ No polo oposto, Alain Guerreau defendeu que, dado o objeto da obra, o livro deveria ter sido intitulado "Descrição da aristocracia e do poder laicos na Europa do século IX ao século XII". ${ }^{8}$ Entre a leitura de um propósito "totalizante" que faz Chirot e a ambição restrita que Guerreau atribui a La sociétéféodale, há um nítido descompasso. Febvre havia identificado uma oposição dessa natureza entre as duas partes do volume 1: "Unidade forte e vigorosa da segunda parte (os laços de homem a homem). Diversidade e, às vezes, ligeira flutuação, da primeira (o meio)". 9 À primeira parte, diz Febvre, bem se poderia ter conferido o título "Notas para a inte-

${ }^{3}$ A instigante questão da construção de uma memória dos Annales na historiografia francesa do século XX foi abordada por François Dosse, A história em migalhas: dos Annales à Nova História [1987], trad., São Paulo/Campinas, Ensaio/UNICAMP, 1992, e por Hervé CoutauBégarie, Le phénomène nouvelle histoire: grandeur et décadence de l'école des Annales, Paris, Economica, 1989.

${ }^{4}$ Marc Bloch, La société féodale [1939-1940], Paris, Albin Michel, 1949, vol. 1, p. 7. Uma referência suplementar, em carta de Marc Bloch a Henri Berr, coordenador da coleção em que sairia La société féodale, reproduz a enunciação do objeto da obra em termos muito próximos. A obra foi concebida, segundo Bloch, "como um ensaio de resposta a um problema único, delimitado na introdução [...]. Eu tentei, pela primeira vez, sem dúvida, analisar um tipo de estrutura social com todas as suas conexões" (Marc Bloch, Écrire La Société féodale: lettres à Henri Berr (1924-1943), Paris, IMEC, 1992, p. 96).

${ }^{5}$ Daniel Chirot, “The social and historical landscape of Marc Bloch”, em Theda Skocpol (org.), Vision and method in historical sociology, Cambridge, Cambridge University Press, 1995, p. 24.

${ }^{6}$ Idem, ibidem.

${ }^{7}$ Ulrich Raulff, Marc Bloch: un historien au XXe siècle [1995], Paris, Éditions de la Maison des sciences de l'homme, 2005, p. 102.

${ }^{8}$ Alain Guerreau, O feudalismo: um horizonte teórico [1980], trad., Lisboa, 70, [s.d.], p. 91.

${ }^{9}$ Lucien Febvre, “Compte-rendu de La societé féodale: la formation des liens de dépendance”, op. cit., p. 40. 
ligência de algumas das características essenciais da civilização medieval". ${ }^{10}$ Somente após as primeiras duzentas páginas o livro entraria em objeto sólido e bem definido. Bloch reagiu à resenha de Febvre em carta de 31 de janeiro de 1940 e assinalou que é preciso ler a obra inteira para entendê-la: "trata-se de um único livro, em dois tomos, e, portanto, de um problema, mais ou menos bem tratado, como tal, mas com um nítido esforço por centrar o estudo em seu foco. A serpente morde sua própria cauda". ${ }^{11}$ Bloch resiste, portanto, à crítica e afirma, com ênfase, que se ocupa de "um problema". Porém, diante da polêmica sobre qual é esse problema, como responder a uma questão aparentemente tão simples: de que trata La société féodale?

Reconhecendo, então, que, em certa medida, "é o ponto de vista que cria o objeto", ${ }^{12}$ voltamo-nos ao problema do instrumental conceitual empregado por Marc Bloch, na esperança de melhor esquadrinhar a proposição da matéria da obra. Porém, deparamo-nos aqui com uma segunda instância de polêmica. À semelhança da antropologia nascente para Les rois thaumaturges - com lacunas sérias, é verdade - e da geografia para Les caractères originaux, ${ }^{13}$ buscou-se o núcleo conceitual que presidiu à realização de La société féodale na sociologia, de forma que já se tenha mesmo afirmado que Bloch foi "um dos pais da sociologia histórica contemporânea". ${ }^{14}$ Mais especificamente, retomando depoimentos do próprio Marc Bloch, essa relação foi entendida como aproximação com a sociologia durkheimiana. ${ }^{15}$ Para Peter Burke, aliás, " $L a$ société féodale é o seu livro mais durkheimiano". ${ }^{16}$ Para além da necessidade reconhecida de se refletir acerca das outras fontes sociológicas em que Bloch

\footnotetext{
${ }^{10}$ Idem, ibidem, p. 42.

${ }^{11}$ Marc Bloch e Lucien Febvre, Correspondance, ed. Bertrand Müller, Paris, Fayard, vol. 1, 1994, p. 79-81, grifos do autor.

${ }^{12}$ Ferdinand de Saussure, Curso de linguística geral [1916], trad., São Paulo, Cultrix/Edusp, 1969, p. 15.

${ }^{13}$ Jacques Le Goff, "Prefácio”, em Marc Bloch, Os reis taumaturgos [1924], trad., São Paulo, Companhia das Letras, 1999, p. 9-37, e Pierre Toubert, “Préface”, em Marc Bloch, Les caractères originaux de l'histoire rurale française, Paris, Armand Colin, 1999, p. 5-41.

${ }^{14}$ Daniel Chirot, “The social and historical landscape of Marc Bloch”, op. cit., p. 92.

${ }^{15}$ Marc Bloch, Apologia da história ou o ofício de historiador [1949], trad., Rio de Janeiro, Jorge Zahar, 2001, p. 47-48. Mas pense-se, também, na carta dirigida por Bloch a Febvre, em 17 de agosto de 1942: "Durkheim certamente não era um imbecil [...] Entretanto, como estamos longe deles” (Marc Bloch e Lucien Febvre, Correspondance, op. cit., vol. 3, 2003, p. 210).

${ }^{16}$ Peter Burke, A escola dos Annales (1929-1989): a revolução francesa da historiografia [1990], trad., São Paulo, UNESP, 1997, p. 36.
} 
teria bebido, tanto as que ele não cita ou muito raramente cita ${ }^{17}$ quanto aquelas a que ele alude em obras mais explicitamente reflexivas, como em sua Apologie pour l'histoire ${ }^{18}$ a relação efetiva com a sociologia durkheimiana continua em discussão. Colbert Rhodes, aproximando conceitos de ambos os autores, identifica uma apropriação quase instantânea dos conceitos durkheimianos por Bloch, ${ }^{19}$ razão pela qual o livro seria, para Bryce Lyon, de reduzido interesse para o medievalista, muito mais cativante para o sociólogo. ${ }^{20}$ Outros preferiram ver a questão com mais cautela. Os prefaciadores de Les rois thaumaturges e Les caractères originaux de l'histoire rurale française viram uma relação bem mais matizada entre Durkheim e Bloch, ${ }^{21}$ posição também defendida no estudo recente de Susan Friedman. ${ }^{22}$

Desse modo, à questão não resolvida a respeito do objeto de La société féodale, soma-se a dificuldade de bem se delimitar o referencial conceitual de que Marc Bloch lança mão. Trata-se, de fato, de questões interdependentes, na medida em que conceito e objeto se constroem mutuamente, o primeiro criando os quadros de observação do segundo, o segundo impelindo sucessivamente à adaptação e reformulação do primeiro. Nesse sentido, a dinâmica entre a circunscrição do objeto e o repertório conceitual empregado/construído coloca em questão todo o movimento intelectual que subjaz à escrita da obra.

17 Jean-Claude Schmitt fala da "flexibilidade do pensamento de Marc Bloch: ela é o corolário de uma imensa erudição duplicada por uma reflexão teórica que sempre guarda o silêncio sobre seus empréstimos, à exceção de Durkheim” (Jean-Claude Schmitt, “Façons de sentir et de penser’: un tableau de la civilisation ou une histoire-problème?”, em Hartmut Atsma e André Burguière (org.), Marc Bloch aujourd'hui: histoire comparée et sciences sociales, Paris, EHESS, 1990, p. 414).

${ }^{18}$ Caso de Auguste Comte (Marc Bloch, Apologia da história, op. cit., p. 47), Georg Simmel (idem, ibidem, p. 158) e, sobretudo, Fustel de Coulanges (idem, ibidem, p. 47, 54, 66, 67, 93, 94, 134, 142), sobre quem Bloch disse, em discurso proferido quando do centenário de seu nascimento, que, "Fustel não gostava simplesmente [do nome sociologia] porque, para ele, a sociologia e a história eram uma só coisa” (Marc Bloch, "Fustel de Coulanges: historien des origines françaises”, Revue internationale de l'enseignement, 50, 1930, p. 176).

${ }^{19}$ R. Colbert Rhodes, "Émile Durkheim and the historical thought of Marc Bloch", Theory and Society, vol. 5, 1978, p. 45-96.

${ }^{20}$ Bryce Lyon, “The feudalism of Marc Bloch” [1963], em: medieval institutions, London, Variorum Reprints, 1978, XII, p. 275-283.

${ }^{21}$ Jacques Le Goff, “Prefácio”, op. cit., p. 14-15, e Pierre Toubert, “Préface”, op. cit., p. 15-16.

${ }^{22}$ Comentando os anos que se seguiram à Primeira Guerra Mundial, a autora observa que "Alguns continuaram interessados no pensamento durkheimiano, mas muitos, como Marc Bloch, trabalhariam nos quadros de outras disciplinas e, ao fazê-lo, reinterpretariam seus métodos e conceitos” (Susan Friedman, Marc Bloch, Sociology and Geography: encountering changing disciplines, Cambridge, Cambridge University Press, 1996, p. 127). 
Na medida em que essas questões permanecem entremeadas de tantas polêmicas e discordâncias, cabe reconhecer que aquela que é provavelmente a obra mais difundida de Marc Bloch permanece sendo sua obra mais fugidia.

Não nos propomos aqui a dar resposta definitiva a esse debate. Bloch ensinava ser mais fértil propor questões que resolvê-las. ${ }^{23}$ Limitar-nos-emos a explorar três oposições conceituais em La sociétéféodale (civilização/estrutura social; sociedade feudal/sociedades medievais; estrutura social/sujeito) e a examinar especificamente a noção de "estrutura social". A discordância na leitura desses termos parece ter estado na raiz de alguns dos desentendimentos apontados; em sua articulação também parece definir-se o objeto da obra. Ao expormos essas noções, tais como se formulam na própria obra de Bloch, recorreremos ao espectro conceitual durkheimiano para sugerir proximidades e afastamentos. Não resolvemos, assim, a questão da apropriação conceitual em Bloch, mas encaminhamos, ao menos, o problema específico da sociologia durkheimiana. Ao final, esperamos ter conseguido desatar alguns mal-entendidos, de forma que as questões indicadas possam ressurgir em toda sua complexidade.

\section{Civilização vs. estrutura social}

A primeira oposição conceitual que, conforme verificamos, tem gerado desconforto entre os leitores de La sociétéféodale no que tange à circunscrição de seu objeto se estabelece entre as noções de civilização e de estrutura social. De fato, apesar do propósito de "análise e explicação de uma estrutura social", ${ }^{24}$ o conceito de civilização é recorrente na obra de Marc Bloch, e muitos acreditam ser de uma civilização que se ocupa o livro. A formulação mais condensada dessa noção encontra-se no opúsculo póstumo Apologie pour l'histoire:

A palavra [civilização], como Lucien Febvre mostrou, só se desvencilhou muito lentamente do juízo de valor. Hoje conquista sua liberdade. [...] Reconhecemos que em uma sociedade, seja qual for, tudo se liga e controla mutuamente: a

${ }^{23}$ Marc Bloch, Les caractères originaux de l'histoire rurale française [1931], Paris, Armand Colin, 1999, p. 45.

${ }^{24}$ Marc Bloch, La société féodale, op. cit., vol. 1, p. 7, grifos nossos. 
estrutura política e social, a economia, as crenças, tanto as formas mais elementares como as mais sutis de mentalidade..$^{25}$

Mas a noção é mais arraigada no pensamento de Bloch, que chegou a falar sobre o campo mesmo da "História da civilização". Propondo um quadro amplo para a compreensão da história rural, Marc Bloch sugere a realização de uma “'História da civilização'. Sim, certamente. Além da estrutura social e da vida agrária no sentido mais estrito, a mentalidade deve ter um grande lugar". ${ }^{26}$ Discorrendo sobre o conceito e falando em uma "civilização medieval", Bloch retoma à ideia em La sociétéféodale, indicando que "a armadura das instituições que comanda uma sociedade não se saberia, em última instância, explicar senão pelo conhecimento de todo o meio humano". ${ }^{27}$ A noção de civilização, portanto, aparece em Bloch como um complexo articulado dos diferentes planos da vida humana, cuja separação constitui verdadeira "ficção de trabalho". ${ }^{28}$ Como demonstram o trecho da Apologie e a proposta de uma "História da civilização", esses diferentes planos do "meio humano" incluem a estrutura social, que se relaciona, assim, com a civilização tal como a parte com o todo. Respondendo à resenha que Febvre fez do segundo tomo de $L a$ société féodale, Bloch lhe escreveu, em carta de maio de 1942: "Eu não quis escrever o estudo de uma civilização. Mas analisar um tipo de estrutura social e explicá-la”. ${ }^{29}$

Ora, que parte, especificamente, da civilização corresponde à "estrutura social"? Noção sutil também e que tendemos a confundir com o "todo civilizacional", na medida em que a história social da segunda metade do século XX tendeu a se conferir um domínio hegemônico sobre os demais recortes de objeto. Na formulação de Albert Soboul, "todo o campo da história, inclusive o

${ }^{25}$ Marc Bloch, Apologia da história, op. cit., p. 152. A referência feita por Bloch a Lucien Febvre é bastante reveladora, pois remete certamente a seu texto "Civilisation: évolution d'un mot et d'un groupe d'idées" - já citado por Bloch em um balanço bibliográfico sobre feudalidade, vassalidade e senhoria muito instrutivo sobre a gênese da Société féodale e ao qual retornaremos mais adiante (Marc Bloch, "Féodalité, vassalité, seigneurie: à propos de quelques travaux récents”, Annales d'histoire économique et sociale, 1931, p. 246) - apresentado como conferência em um simpósio realizado pelo Centre International de Synthèse, em maio de 1929 (publicado como Civilisation: le mot, l’idée, Paris, La Renaissance du Livre, 1930).

${ }^{26}$ Apud Susan Friedman, Marc Bloch, Sociology and History, op. cit., p. 162.

${ }^{27}$ Marc Bloch, La société féodale, op. cit., vol. 1, p. 95.

${ }^{28}$ Idem, ibidem.

${ }^{29}$ Marc Bloch e Lucien Febvre, Correspondance, op. cit., vol. 3, p. 197. 
mais tradicional, faz parte da história social", ${ }^{30}$ formulação complexa que ganha contornos muito distintos dependendo daquilo que se entende por "social" e noções correlatas. No caso de Bloch, o plano da estrutura social aparece de forma mais limitada. Apesar de não dispormos de formulações tão explícitas por parte de Bloch, poderíamos entendê-lo, a princípio, como compreendendo uma rede de vínculos concretos entre homens. Voltaremos a essa definição, para precisá-la, mais à frente (cf. infra, item 4). ${ }^{31}$

Estabelece-se, de todo modo, uma relação hierárquica entre a civilização e a estrutura social, o que permite, aliás, o recorte desta no interior daquela. Como afirma o historiador em La société féodale, "a ficção de trabalho que, no homem de carne e de sangue, constrange-nos a separar esses fantasmas: homo oeconomicus, philosophicus, juridicus, é necessária sem dúvida". ${ }^{32}$ A ideia será posteriormente retomada na Apologie:

Nada mais legítimo, nada mais saudável do que centrar o estudo de uma sociedade em um desses aspectos particulares, ou, melhor ainda, em um dos problemas precisos que levanta este ou aquele desses aspectos: crenças, estruturas das classes ou dos grupos, as crises políticas [...]. ${ }^{33}$

Como, então, compreender as duzentas primeiras páginas de La société féodale, em que Febvre via descontinuidade surpreendente com relação ao restante da obra? Isto é, por que, antes de se dirigir especificamente à estrutura social que anunciou na introdução, Marc Bloch se põe a tratar das "últimas invasões" e das "condições de vida e atmosfera mental", questões relacionadas a outros planos da civilização, da totalidade histórica? Bloch formula a questão nos seguintes termos: "pontos de chegada com relação a outras pesquisas diversamente direcionadas, a análise da economia ou da mentalidade são, para o historiador da estrutura social, um ponto de partida". ${ }^{34}$ Ou seja, os

${ }^{30}$ Albert Soboul, “Descrição e medida em história social”, em A história social: problemas, fontes e métodos (Colóquio de Saint-Cloud, 1965) [1967], trad., Lisboa, Cosmos, 1973, p. 25.

${ }^{31}$ Entretanto, cabe desde já apontar a descontinuidade entre a noção de sociedade e a de estrutura social para Bloch. Como se pode observar, na definição de civilização que consta da Apologie, sociedade aparece como um sinônimo desse termo. Porém, como verificaremos no próximo item, "sociedade" também pode significar um vínculo específico, denotado pela adjetivação que se combina com o termo, caso de "sociedade feudal". "Estrutura social", no entanto, não assume nem um nem outro desses sentidos; não é vínculo específico nem se confunde com o conjunto civilizacional.

${ }^{32}$ Marc Bloch, La société féodale, op. cit., vol. 1, p. 95.

${ }^{33}$ Marc Bloch, Apologia da história, op. cit., p. 134-135.

${ }^{34}$ Marc Bloch, La société féodale, op. cit., vol. 1, p. 96. 
outros domínios que compõem o todo civilizacional - como a economia e a mentalidade - não se configuram como objeto da investigação, como "pontos de chegada". Sua posição é outra, de ordem relacional com o fenômeno estudado, como "pontos de partida". O papel da relação que o objeto específico "estrutura social" estabelece com a totalidade da "civilização" é de ordem explicativa. Repetimos a citação transcrita anteriormente: "a armadura das instituições que comanda uma sociedade não se saberia, em última instância, explicar senão pelo conhecimento de todo o meio humano". 35

Reencontramos aqui, ao que parece, o significado da expressão "com suas conexões (liaisons)", ${ }^{36}$ que consta na enunciação do propósito da obra. Marc Bloch abordaria justamente nesses termos a questão das "conexões", ou "ligações", na Apologie, citando Michelet e Fustel de Coulanges para concluir que "uma civilização nada tem de um jogo de paciência, mecanicamente arranjado; o conhecimento dos fragmentos, sucessivamente estudados, cada um por si, jamais propiciará o do todo; não propiciará sequer o dos próprios fragmentos". ${ }^{37} \mathrm{Ou}$ seja, ainda que lhe pareça "legítimo" e "saudável" recortar domínios específicos do "meio humano" para estudo, ao cabo, os diferentes planos se explicam em função da inter-relação que estabelecem uns com os outros, no conjunto do domínio civilizacional. A noção lhe é cara, e é por meio dela que critica Calmette, que, em seu Le monde féodal, não teria se dedicado, segundo Bloch, às "ligações (liaisons) entre os diversos tipos de fenômenos";38 no mesmo ano, em carta a Henri Pirenne, ao falar de quanto trabalha em $L a$ société féodale, destaca: "Esses fatos são tão imbricados uns nos outros!". ${ }^{39}$

Nesse sentido, a estrutura social, como parte integrante do todo civilizacional, não se explica em razão de um funcionamento próprio e independente dos outros domínios da vida humana. Adotando essa posição, Marc Bloch confere um caráter multiexplicativo aos fenômenos específicos da estrutura social. Nessa atitude, localiza-se uma primeira cisão fundamental com relação à sociologia de Durkheim. Para o sociólogo, os fatos sociais têm sempre uma

\footnotetext{
${ }^{35}$ Idem, ibidem, vol. 1, p. 95.

${ }^{36}$ Idem, ibidem, vol. 1, p. 7.

${ }^{37}$ Marc Bloch, Apologia da história, op. cit., p. 134.

${ }^{38}$ Marc Bloch, “Compte-rendu de Joseph Calmette, Le monde féodal”, Annales d'histoire économique et sociale, 6, 1934, p. 380.

${ }^{39}$ Lucien Febvre, Marc Bloch e Henri Pirenne, The birth of Annales history. The letters of Lucien Febvre and Marc Bloch to Henri Pirenne, ed. Bryce e Mary Lyon, Bruxelas, Commission royale d'histoire, 1991, p. 160.
} 
"causa eficiente" social e uma "função" social: "a causa determinante de um fato social deve ser buscada entre os fatos sociais antecedentes [...] a função de um fato social deve sempre ser buscada na relação que ele mantém com algum fim social". ${ }^{40}$ Assim, ao passo que Durkheim "ensimesma" o social, explicando-o exclusivamente em função de fatores da mesma ordem específica, Bloch interpenetra os diversos planos civilizacionais no movimento explicativo, explicando a estrutura social também em função de outros domínios do meio humano. Essa distinção, conforme veremos mais adiante, remete às descontinuidades entre a "estrutura social", tal qual a entende Bloch, e a noção de sociedade tal qual pensada por Durkheim. Segundo Susan Friedman, Bloch "buscou explicar fenômenos individuais, [...], e nessa tentativa propôs recorrer tanto a causas ocasionais como profundas, ligando fenômenos de ordens distintas e, assim, mais uma vez indo contra princípios durkheimianos". ${ }^{41}$

Assim, propomos reconsiderar a enunciação que Bloch dá do objeto de La sociétéféodale. Esclareçamos, antes, o significado do primeiro termo daquela enunciação, em que ainda não tocamos. Trata-se da "análise". Ora, na Apologie, Marc Bloch dedicou todo um capítulo à "análise histórica". ${ }^{42} \mathrm{O}$ significado do termo é precisado em estreita correlação com a noção de "conexão", ou "ligação", sobre a qual já discorremos. Escreve Bloch:

Mas o trabalho de recomposição... só poderia vir depois da análise, como sua razão de ser. Na imagem primitiva, antes contemplada do que observada, como teriam sido discernidas as ligações, já que nada se distinguia? Sua rede delicada só podia aparecer uma vez os fatos classificados por linhagens específicas. ${ }^{43}$

Ou seja, a análise é o recorte do específico no meio da totalidade das ligações. Sugerimos, assim, entender o objeto de La société féodale da seguinte maneira: o recorte ("análise") de um domínio específico ("estrutura social”) no interior de um todo civilizacional e sua "explicação", que só pode se dar na consideração das relações do domínio específico com o todo ("com suas conexões").

\section{Sociedade feudal vs. sociedades medievais}

Entendendo, assim, que não é da civilização que se ocupa a obra, referência necessária em caráter explicativo, mas apenas "ponto de partida” com

\footnotetext{
${ }^{40}$ Émile Durkheim, As regras do método sociológico [1895], trad., São Paulo, Martins Fontes, 1999, p. 112.

${ }^{41}$ Susan Friedman, Marc Bloch, sociology and history, op. cit., p. 111-112.

${ }^{42}$ Marc Bloch, Apologia da história, op. cit., p. 125-153.

${ }^{43}$ Idem, ibidem, p. 134.
} 
relação ao plano específico que constitui o objeto do livro, a estrutura social, surge mais um problema conceitual: essa estrutura social está indicada, no título do livro, pela expressão "sociedade feudal". Qual a relação precisa entre essas duas nomeações do objeto, uma mais geral (estrutura social), a outra mais específica (sociedade feudal)? À parte a noção de "sociedade", a que já aludimos e que discutiremos na sequência, a própria adjetivação "feudal" deixa largo espaço para questionamento e dúvida. Marc Bloch, após discutir brevemente a história dos termos "feudalidade" e "sociedade feudal", assume "tratar essas expressões simplesmente como a etiqueta, desde agora consagrada, de um conteúdo a ser definido". ${ }^{44}$ Essa definição não deve ser, de modo algum, eternamente postergada, atitude que Febvre pensava detectar no livro do amigo. ${ }^{45}$ Já em 1931, aliás, Bloch definira em termos muito próximos o problema do termo feudalidade e criticara vários historiadores, começando por Otto Hintze, ${ }^{46}$ por não terem "determinado, finalmente, o sentido dessa palavra equívoca, e posto fim ao mal-entendido que se abate sobre tantos estudos de história social". ${ }^{47}$ A questão que desponta é, assim, a seguinte: na concepção de La sociétéféodale, de que maneira o epíteto "feudal" interfere no recorte da estrutura social do conjunto da civilização? Bryce Lyon admitiu aí a existência de uma ambiguidade, levada a cabo na exposição do livro: "[Marc Bloch] nunca conseguiu se decidir por estudar essa estrutura social ou por associá-la à estrutura social total de uma civilização". ${ }^{48}$ Tratar-se-ia, assim, do estudo da totalidade da estrutura social de uma civilização, compreendendo todos os vínculos e formas de agrupamento, a totalidade das relações humanas, ou de uma parcela delas? Alain Guerreau entendeu que o recorte recaía exclusivamente sobre a aristocracia laica, vendo nisso um descompasso com o título La société féodale. ${ }^{49}$ Entretanto, Bloch, na polissemia do termo feudal, reservou-se o direito de definir o conteúdo na exposição. Antes de sentenciarmos, portanto, a inadequação do título ao conteúdo ou de admitirmos uma flutuação no decorrer da exposição, temos de buscar averiguar qual foi o

\footnotetext{
${ }^{44}$ Marc Bloch, La société féodale, op. cit., vol. 1, p. 3.

${ }^{45}$ Lucien Febvre, "Compte-rendu de La societé féodale: la formation des liens de dépendance", op. cit., p. 41, acha que há uma "insuficiência de precisões na partida", e é como se esse conteúdo estivesse sempre por se definir e nunca se definisse.

${ }^{46} \mathrm{O}$ artigo de Hintze a que Bloch se refere foi recentemente traduzido para o português: Otto Hintze, “Natureza e extensão do feudalismo” [1929], Signum, 6, 2004, p. 145-182.

${ }^{47}$ Marc Bloch, “Féodalité, vassalité, seigneurie”, op. cit., p. 247.

${ }^{48}$ Bryce Lyon, “The feudalism of Marc Bloch”, op. cit., p. 278-279.

${ }^{49}$ Alain Guerreau, O feudalismo, op. cit., p. 91.
} 
conteúdo disposto por Bloch sob aquela "etiqueta". Afinal, já em 1931, Bloch não cobrava - como não costumava fazer - uma definição a priori da "feudalidade", mas criticava os estudos que, tendo se debruçado sobre ela, não tinham chegado, como resultado, a uma definição, especialmente os estudos de "estrutura social", como a sua Société féodale. ${ }^{50}$

$\mathrm{Na}$ Apologie, Bloch, ao falar da importância do emprego rigoroso das palavras pelo historiador, faz menção justamente aos problemas suscitados pelo emprego do epíteto "feudal". Escreve ele:

O uso, até nos historiadores, tende a confundir, da maneira mais desagradável, as expressões "regime feudal" e "regime senhorial". É assimilar arbitrariamente, à rede de vínculos de dependência característica de uma aristocracia guerreira, um tipo de sujeição camponesa que, muito diferente por natureza, nasceu, além disso, muito mais cedo, durou muito mais tempo e foi, mundo afora, muito mais difundido. ${ }^{51}$

Formula-se aí, de forma clara, a separação entre uma parcela da estrutura social que recebe o nome "feudal" - a "rede de vínculos de dependência característica de uma aristocracia guerreira" - e outros vínculos concomitantes, ou seja, outras parcelas da estrutura social de uma mesma civilização. De forma coerente com essa observação posterior, Bloch fala dos "dois fatores [que] parecem ter sido indispensáveis a todo regime feudal acabado: o quase monopólio profissional do vassalo-cavaleiro; e o apagamento, mais ou menos voluntário, diante do vínculo vassálico, dos outros meios de ação da autoridade pública" ${ }^{52}$ A referência aqui recai sobre um vínculo bastante específico, o feudo-vassálico, núcleo da análise já no artigo "European feudalism”, escrito em 1931 para a Encyclopaedia of social sciences. ${ }^{53}$ No conjunto da estrutura social, portanto, há um recorte específico que carrega o nome "feudal", a relação feudo-vassálica, característica, em determinado momento, de uma forma peculiar de relacionamento no interior da aristocracia laica. É aí, ao que parece, que devemos buscar o objeto de La sociétéféodale.

Entretanto - e tal é o fundamento da ambiguidade que Bryce Lyon crê existir -, na obra, o vínculo feudo-vassálico aparece associado a diversas

\footnotetext{
${ }^{50}$ Marc Bloch, “Féodalité, vassalité, seigneurie”, op. cit., p. 247.

${ }^{51}$ Marc Bloch, Apologia da história, op. cit., p. 143, grifos nossos.

${ }^{52}$ Marc Bloch, La société féodale, vol. 1, p. 289.

${ }_{53}$ Marc Bloch, “European feudalism” [1931], em: Mélanges historiques, Paris, S.E.V.P.E.N., vol.1, 1963, especialmente p. 180.
} 
outras modalidades de relação social. Como discutimos, a referência a domínios distintos de seu objeto imediato não configura incoerência para Bloch, que percebe os diferentes fenômenos sob o signo da noção de "liaisons", em função das conexões que estabelecem com outros fenômenos. Essa relação tem, sobretudo, como vimos, um caráter explicativo. Nesse sentido, cabe reconhecer que os outros vínculos são sempre discutidos na relação que mantêm com o feudo-vassálico. É o caso de (1) o parentesco, cuja "fraqueza relativa explica que tenha havido uma feudalidade", ${ }^{4}$ (2) o senhorialismo, "personagem bastante mais velha que as instituições verdadeiramente características da primeira idade feudal"; 55 (3) o clero, que foi "forçado [...] a encontrar o seu lugar na estrutura característica da sociedade feudal", ${ }^{6}$ e (4) "as classes profissionais", cujo espaço de atuação privilegiada, a cidade, existiu "na sociedade feudal, como um corpo estranho". ${ }^{57}$ Os outros vínculos são, assim, relacionados e contrapostos ao feudo-vassálico.

Porém, mais especificamente, qual é o significado dessa relação e qual é o papel do vínculo feudo-vassálico, como objeto primordial de investigação? Segundo Bloch, "essa ligação [o vínculo feudo-vassálico] era sentida como sendo tão forte, que sua imagem se projetava sobre todos os outros vínculos humanos". ${ }^{58} \mathrm{O}$ papel dessa relação específica com relação às demais é, portanto, de caráter estruturante. Assim, o parentesco e o senhorialismo, relações mais antigas e que duraram por mais tempo, foram, durante o período em que vicejaram as relações feudo-vassálicas, aproximados, em suas características, daquele vínculo. ${ }^{59}$ No caso do clero, Bloch constata a "extraordinária tenacidade de que fazem prova, até na sua extensão a uma sociedade de essência espiritual, as representações da feudalidade". ${ }^{60}$ No bojo das demais formas de relação social, a relação feudo-vassálica assume, assim, papel preponderante e articulador.

Tratar-se-ia, para Bloch, de um "mundo que se inclinava a conceber todos os laços de homem a homem sob a imagem do mais sedutor deles [o

\footnotetext{
${ }^{54}$ Marc Bloch, La société féodale, op. cit., vol. 1, p. 221.

${ }^{55}$ Idem, ibidem, vol. 1, p. 379, grifos nossos.

${ }^{56}$ Idem, ibidem, vol. 2, p. 101.

${ }^{57}$ Idem, ibidem, vol. 2, p. 114.

${ }^{58}$ Idem, ibidem, vol. 1, p. 356.

${ }^{59}$ Idem, ibidem, vol. 1, p. 220, 428.

${ }^{60}$ Idem, ibidem, vol. 2, p. 111.
} 
feudo-vassálico]". ${ }^{61}$ Esse vínculo teria sido um verdadeiro "cimento social" com relação às outras formas de interação humana. ${ }^{62}$ É nesse sentido que, cremos, deve entender a caracterização que Bloch faz da "sociedade feudal" como "uma sociedade fragmentada e fundamentalmente una", ${ }^{63}$ estrutura social plural, mas balizada por um centro de gravidade - o vínculo feudo-vassálico. Era já esse o sentido do vínculo para Bloch, em 1931, quando definiu "feudalismo" da seguinte maneira: "aquela gradação de obrigações que, na Europa, preservou a homogeneidade da organização política". ${ }^{64}$ Ele "fornecia, [...], pelo jogo das instâncias, um remédio contra o fracionamento". ${ }^{65}$ Criava, por sua força, unidade em meio à pluralidade da estrutura social. Nesse sentido, não nos parece haver ambiguidade no tratamento dispensado por Bloch à estrutura social, nem mesmo incoerência entre o conteúdo da obra e seu título. No conjunto da estrutura social de uma civilização, Bloch recorta um vínculo específico - o feudo-vassálico -, a sociedade "feudal", como contraposta a outros vínculos, que, significativamente, Bloch não hesita em denominar "sociedades", caso da "sociedade clerical". ${ }^{66}$ Isso porque esse vínculo ocupa uma posição estruturante no conjunto da estrutura social.

Cabe indicar que essa concepção a respeito do vínculo feudo-vassálico, visto como centro gravitacional de toda uma estrutura social, é uma descontinuidade com o pensamento anterior de Bloch, questão que não podemos desenvolver aqui, pois mereceria um tratamento do problema no conjunto da produção de Bloch, o que evidentemente foge a nossos propósitos. Ainda no artigo bibliográfico de 1931, em que a noção de "estrutura social” já era determinante, Bloch era da opinião de que "o feudo, de que a feudalidade tira o seu nome, não era, em suma, senão uma forma de direito real, dentre muitas outras, e não tinha qualquer caráter dominante, próprio a servir de sinal distintivo a toda uma rede, extremamente complexa, de relações humanas". ${ }^{67}$ Aqui ainda se está diante do Bloch que vê, mesmo nos séculos da "civilização feudal", a relação senhorial como a preponderante. Ao longo dessa década, todavia, no decorrer de sua redação de La société féodale, Bloch mudou de

\footnotetext{
${ }^{61}$ Idem, ibidem, vol. 2, p. 104.

${ }^{62}$ Idem, ibidem, vol. 1, p. 354; vol. 2, p. 248.

${ }^{63}$ Idem, ibidem, vol. 1, p. 402.

${ }^{64}$ Marc Bloch, “European feudalism”, op. cit., p. 185.

${ }^{65}$ Marc Bloch, La société féodale, vol. 2, p. 140.

${ }^{66}$ Idem, ibidem, vol. 2, p. 104, grifos nossos.

${ }^{67}$ Marc Bloch, “Féodalité, vassalité, seigneurie”, op. cit., p. 246.
} 
opinião - sem que possamos identificar claramente o ponto de ruptura, o que sugere se tratar de uma mudança gradual, mais que de um ponto nítido de inflexão - e passou a conferir à relação feudo-vassálica o lugar central no seio dessa estrutura social.

\section{Estrutura social vs. sujeito}

Há mais uma questão fundamental na tradição de leitura de La société féodale, que gostaríamos de abordar. Novamente, voltamo-nos à leitura inaugural de Febvre, que, ainda aqui, parece estar na raiz de um mal-entendido. Resenhando o segundo tomo de La sociétéféodale, Febvre identifica mais uma ambiguidade no encaminhamento de Bloch. Apesar de reconhecer a existência de indicações na obra de Bloch a respeito de sua importância, para Febvre, "o indivíduo está praticamente ausente" dela. ${ }^{68}$ Para Colbert Rhodes, o indivíduo não se faria presente na obra porque, para Bloch, "o indivíduo aparecia como um receptor irrefletido da conscience collective e das instituições de sua era", subsumido pela estrutura social. ${ }^{69}$ Coloca-se, assim, mais uma questão a ser confrontada com a obra: qual seria, para Bloch, o papel do indivíduo, ou do sujeito, em uma estrutura social particular? Mais diretamente, qual é a sua posição no vínculo específico de que se ocupa?

A questão é pertinente e merece atenção, tendo em vista que o autor assinalou, em La société féodale, como característica fundamental do vínculo feudo-vassálico, a "subordinação de indivíduo a indivíduo" ${ }^{70}$ De fato, há uma série de indicações a respeito da importância específica e fundamental do sujeito no interior da estrutura social. Trata-se, para Bloch, de uma "sociedade em que os vínculos de homem a homem" eram particularmente fortes. ${ }^{71}$ De acordo com o caráter estruturante e modelar que vimos assumir, para Bloch, o vínculo feudo-vassálico com relação aos outros vínculos, a posição social do camponês para com o seu senhor define-se "mais e mais... por sua sujeição com relação a outro homem", ${ }^{72}$ situação que se modificaria quando "a instituição senhorial saiu da feudalidade". ${ }^{73}$ Essa importância especial do elo

\footnotetext{
${ }^{68}$ Lucien Febvre, "Compte-rendu de La société féodale: les classes et le gouvernement des hommes”, Annales d'histoire sociale, 3, 1941, p. 128.

${ }^{69}$ R. Colbert Rhodes, “Émile Durkheim...”, op. cit., p. 68.

${ }^{70}$ Marc Bloch, La société féodale, vol. 1, p. 224.

${ }^{71}$ Idem, ibidem, vol. 2, p. 131.

${ }^{72}$ Idem, ibidem, vol. 1, p. 393.

${ }^{73}$ Idem, ibidem, vol. 1, p. 421.
} 
estabelecido "de homem a homem", sujeito a sujeito, teria sido responsável pelo fato de que aquela estrutura social esteve "longe de constituir a armadura quase única da sociedade e do Estado". ${ }^{74}$ Aquela que é, para Bloch, uma das características essenciais do período, o retraimento do Estado e da autoridade pública, ${ }^{75}$ esteve diretamente relacionada ao papel especialmente forte dos sujeitos no vínculo estruturante daquela sociedade. Para Bloch, "separava-se mal a imagem concreta do chefe da ideia abstrata do poder". ${ }^{76}$

Nesse sentido, sustenta-se mal a ideia de que o papel dos sujeitos é subsumido por Bloch no conjunto da estrutura social. Resta averiguar, mais especificamente, de que modo Bloch concebia a relação entre essas instâncias. A esse respeito, chama atenção o fato de que, tanto em La sociétéféodale ${ }^{77}$ como no artigo que escrevera em 1931 sobre o feudalismo europeu, ${ }^{78}$ Bloch acentue a importância da constituição do vínculo feudo-vassálico como um contrato sinalagmático, acordo estabelecido entre sujeitos, envolvendo direitos e deveres mútuos. Em torno dessa ideia, articulam-se algumas questões de importância capital para a resolução de nosso problema. Bloch concebe esse vínculo contratual como produto deliberado da vontade individual dos contratantes. É nesse sentido que talvez devamos entender sua preocupação, desde 1912, com a questão da exfestucatio, a ruptura voluntária pelo vassalo de seu vínculo com o senhor. ${ }^{79}$ Mais importante é o fato de Bloch associar à limitação desse componente de vontade o declínio do vínculo. Quando elementos externos à vontade dos contratantes se impuseram, o vínculo se descaracterizou. É dessa ordem a interferência do desenvolvimento da hereditariedade ${ }^{80}$ e da transformação da "nobreza de fato em nobreza de direito", em associação com a codificação jurídica. ${ }^{81}$ Desse modo, o sujeito não tem apenas seu papel garantido em La société féodale porque o vínculo característico dessa estrutura

\footnotetext{
${ }^{74}$ Idem, ibidem, vol. 1, p. 289.

${ }^{75}$ Idem, ibidem, vol. 2, p. 219.

${ }^{76}$ Idem, ibidem, vol. 2, p. 197.

${ }^{77}$ Idem, ibidem, vol. 2, p. 257-260.

${ }^{78}$ Marc Bloch, “European feudalism”, op. cit., p. 188.

${ }^{79}$ Marc Bloch, “Les formes de la rupture de l'hommage dans l’ancien droit féodal” [1912], em: —, Mélanges historiques, Paris, S.E.V.P.E.N., vol.1, 1963, p. 189-209. A questão é retomada em La société féodale, op. cit., vol. 1, p. 351-352.

${ }^{80}$ Em Marc Bloch, “European feudalism”, op. cit., p. 184, “A hereditariedade, entretanto, ao mesmo tempo em que selava o feudalismo, certamente comprometia seus próprios fundamentos".

${ }^{81}$ Marc Bloch, La société féodale, vol. 2, p. 58-77.
} 
social é pessoalmente estabelecido. O vínculo é, fundamentalmente, criado pela vontade individual, pela ação dos sujeitos, questão que, na lógica do papel modelar desempenhado pelo vínculo feudo-vassálico, reflete-se nas demais relações, caso do senhorialismo. Segundo Bloch, a importância das senhorias "devia-se, a princípio, aos poderes de comando que ela supunha sobre outros homens. Houve jamais motivo de maior prestígio do que poder dizer "eu quero'?" 82 No caso do laço feudo-vassálico, a vontade estaria nos dois polos da relação.

Nesse ponto, localiza-se uma segunda grande tensão entre as posições expressas por Bloch em La société féodale e a sociologia durkheimiana. Para o sociólogo, o fato social consistiria em "maneiras de agir, de pensar e de sentir, ${ }^{83}$ exteriores ao indivíduo, e que são dotadas de um poder de coerção em virtude do qual esses fatos se impõem a ele" ${ }^{84}$ Mais ainda, segundo Durkheim acrescenta no prefácio à segunda edição de Les règles de la méthode sociologique, trata-se de instâncias que "o indivíduo (...) encontra inteiramente formadas e não pode fazer que elas não existam ou que sejam diferentes do que são". ${ }^{85} \mathrm{Na}$ avaliação que Bloch faz, na Apologie, de seus colegas historiadores, diz que alguns deixaram de lado "uma boa parte da vida mais intimamente individual. Essa foi, em suma, a posição da escola sociológica fundada por Durkheim". ${ }^{86}$

Para Durkheim, diante do fato social, a ação dos sujeitos se apaga. Para Bloch, ao contrário, o fato social específico de que se ocupa explica-se na medida em que resulta da ação individual. Susan Friedman notou com justeza essa diferença. Segundo a autora, Bloch "era claramente interessado no papel do agenciamento humano e relutava em aceitar o argumento de Simiand [economista durkheimiano] de que se deve evitar a explicação de fenômenos sociais por meio de motivos e objetivos" ${ }^{87}$ A crítica a esse ponto da teoria durkheimiana é quase um topos por si só nos escritos de Bloch, como se vê na ligação que ele faz entre uma constatação prosaica, as diferenças de personalidade entre os membros de sua própria família, e a perspectiva teórica de Durkheim, em

\footnotetext{
${ }^{82}$ Idem, ibidem, vol. 2, p. 11.

${ }^{83}$ Como não relacionar essa formulação com o título do segundo capítulo do livro "As condições de vida e a atmosfera mental”, o segundo livro dos oito que compõem La société féodale, o sugestivo "Maneiras de sentir e de pensar"?

${ }^{84}$ Émile Durkheim, As regras do método sociológico, op. cit., p. 3.

${ }^{85}$ Idem, ibidem, p. xxix.

${ }^{86}$ Marc Bloch, Apologia da história, op. cit., p. 47-48.

${ }^{87}$ Susan Friedman, Marc Bloch, sociology and history, op. cit., p. 132.
} 
carta a Febvre: "cada um [é] moralmente e intelectualmente, tão diferente dos outros, que parece um desmentido perpétuo do durkheimismo". ${ }^{88}$ De um ponto de vista mais teórico e menos pitoresco, "sempre será melhor atingir uma coletividade por um indivíduo", ${ }^{89}$ algo absolutamente impensável no construto durkheimiano, na medida em que indivíduo e sociedade pertencem aí a ordens distintas da realidade, todo fato social devendo se explicar por um fato social. De acordo com Bloch, ao contrário, como já vimos, são as ligações (liaisons) entre ordens de fatos distintas, como o sujeito e a estrutura social, que permitem a explicação histórica (cf. supra, item 1).

Para Bloch, esse papel do sujeito pode, ao cabo, balizar toda uma estrutura social. Na sociedade feudal, tal qual a concebe o historiador, o caminho da coerção durkheimiana, sociedade $\rightarrow$ indivíduo, inverte-se: naquela estrutura social, a ação do sujeito, nos quadros do vínculo feudo-vassálico, adquire a dimensão de pedra de toque da organização social. Mais ainda - e é com essas palavras que se fecha La sociétéféodale -, é por meio da dimensão voluntária e pessoal do contrato feudo-vassálico que, "por mais duro que esse regime tenha sido para com os pequenos, ele realmente legou às nossas civilizações algo de que ainda desejamos viver". ${ }^{90}$

\section{A noção de "estrutura social"}

No item 1, havíamos nos comprometido a retomar a noção de "estrutura social" para melhor precisá-la. Trata-se de questão crucial, pois é por essa expressão que Bloch nomeia seu objeto de estudo. Deixamos essa questão para este momento da exposição, tanto porque seu encaminhamento depende das demais categorias examinadas, como porque, de fato, a noção de "estrutura social" não é formulada por Bloch com a precisão conceitual que o leitor talvez desejasse. Em carta dirigida a Lucien Febvre, em 5 de fevereiro de 1933, Bloch, sabendo que Ferdinand Lot desistira de escrever seu volume para a coleção de Henri Berr, sugere seu próprio nome, apesar de já haver sido comissionado para dois volumes sobre a economia medieval (que não seriam nunca terminados). Na hora de se justificar, associando o objeto dos livros já encomendados àquele do qual se propõe autor (o futuro La société féodale), Bloch escreve: "Em certo sentido, ser-me-ia mais fácil tratar em conjunto

\footnotetext{
${ }^{88}$ Marc Bloch e Lucien Febvre, Correspondance, op. cit., vol. 2, p. 287.

${ }^{89}$ Idem, ibidem, vol. 1, p. 430.

${ }^{90}$ Marc Bloch, La société féodale, vol. 2, p. 260.
} 
a sociedade medieval sob seus dois aspectos: econômico e [...] como dizer? Escolhamos "estrutural" ${ }^{91}$ Esse trecho, em que a hesitação em rotular seu objeto é explícita, permite entrever a gênese de uma fórmula que seria, a partir daí, associada ao conteúdo do livro, como se percebe já três dias depois, na carta de agradecimento a Henri Berr por tê-lo aceito para esse terceiro livro: "Eu penso que o senhor estará de acordo comigo para entender meu volume como sendo antes de tudo um estudo de estrutura social". 92 Em um conjunto de documentos de Bloch, que se encontravam em Moscou desde a década de 1940 e que só foram restituídos à França em 1994, consta uma anotação, em manuscrito de La société féodale, em que Bloch descreve o empreendimento de La société féodale como uma tentativa de "desmontagem de uma estrutura social" ${ }^{93}$ E é essa noção que aparece na carta a Febvre, em resposta à resenha do segundo tomo da obra, na qual Bloch insiste que ele quis foi "analisar um tipo de estrutura social e explicá-la". ${ }^{44}$ Assim, desde que concebeu a sua Société féodale até depois de sua publicação, dez anos mais tarde, percebe-se que Bloch se ateve a essa noção. Pode parecer paradoxal, assim, que ele não tenha formulado uma definição precisa do que entendia por "estrutura social”, mas, pela forma "tateada" com que chegou a ela na carta endereçada a Febvre - apesar de não ter apenas então adotado a noção de "estrutura social" em sua obra -, percebemos que Bloch levava a sério seu próprio conselho de que as noções do historiador devem ser flexíveis, "como todo conceito que tenta exprimir, sem deformá-las, as coisas do homem". ${ }^{5}$

Porém, mesmo na ausência de uma definição precisa, podemos entrever algumas das ideias que a noção de "estrutura social" faz ecoar no texto de Bloch, conforme algumas das demais categorias selecionadas para exame neste texto já sugeriram, todas dependentes do objeto da obra, a "estrutura social". Em comunicação de 1942 sobre "As transformações das técnicas como problema de psicologia coletiva", Bloch fala dos "fatos de estrutura social", relacionando-os ao seguinte desenvolvimento:

Quando as classes se fecham umas às outras, quando as classes mais ricas e mais poderosas deixam de comunicar com aquelas que, na hierarquia das fortunas, es-

\footnotetext{
${ }^{91}$ Marc Bloch e Lucien Febvre, Correspondance, v. 1, p. 330.

${ }^{92}$ Marc Bloch, Écrire La société féodale, op. cit., p. 76.

${ }^{93}$ Apud Ulrich Raulff, Marc Bloch, op. cit., p. 180.

${ }^{94}$ Marc Bloch e Lucien Febvre, Correspondance, op. cit., vol. 3, p. 197.

${ }^{95}$ Marc Bloch, Apologia da história, op. cit., p. 152.
} 
tão colocadas abaixo delas, sem dúvida, os elementos dirigentes são levados a considerar como indigno de sua atenção tudo o que concerne à materialidade do trabalho. ${ }^{96}$

Trata-se, portanto, de referência explícita às relações entre grupos; mas não apenas. Como vimos, no caso de La société féodale, a ênfase recai particularmente sobre o indivíduo e sua posição no conjunto das relações sociais. É interessante, a esse propósito, que Bloch prefira falar, em La société féodale, na "constituição dos laços de homem para homem, os quais, acima de tudo, conferiram à estrutura feudal a sua cor própria", ${ }^{97}$ uma formulação correlata àquela que lhe faz definir, na Apologie, a história como o "estudo dos homens no tempo", ${ }^{98}$ não exclusivamente dos grupos sociais, não exclusivamente dos indivíduos, mas dos homens.

É, aliás, na combinação de categorias pessoais e grupais, que Bloch, no começo do segundo tomo da obra, fornece um resumo de La société féodale, remetendo à pluralidade das modalidades de vínculo que compõem a estrutura social de que se ocupa:

Uma rede de laços de dependência, tecendo os seus fios de alto a baixo da escala humana, conferiu à civilização da feudalidade europeia a sua marca mais original. Como, sob a ação de que circunstâncias e de que ambiente mental, auxiliada também por quais empréstimos, tomados de um passado mais distante, essa estrutura tão especial pôde nascer e evoluir, é o que nos esforçamos por mostrar em um volume precedente. No entanto, nunca nas sociedades às quais se dá tradicionalmente o epíteto de 'feudais', os destinos individuais tinham sido regidos exclusivamente por essas relações de sujeição próxima ou de comando imediato. Os homens repartiam-se nelas também em grupos, situados uns acima dos outros, diferenciados pela vocação profissional, pelo grau de poder ou de prestígio. Além disso, acima da poeira das inúmeras circunscrições, de toda espécie, subsistiram sempre poderes de raio mais amplo e de natureza diferente. A partir da segunda idade feudal, vemos, ao mesmo tempo, as classes se ordenarem mais estreitamente e operar-se com vigor crescente a concentração das forças, em torno de algumas grandes autoridades e de algumas grandes aspirações. ${ }^{99}$

\footnotetext{
${ }^{96}$ Marc Bloch, “As transformações das técnicas como problema de psicologia coletiva” [1948], trad., Signum, 1, 1999, p. 180, grifos nossos.

${ }^{97}$ Marc Bloch, La société féodale, op. cit., vol. 1, p. 7.

${ }^{98}$ Marc Bloch, Apologia da história, op. cit., p. 55.

${ }^{99}$ Marc Bloch, La société féodale, op. cit., vol. 2, p. 21.
} 
Como se depreende desse trecho, a "estrutura social" diz respeito às relações entre os homens (indivíduos e grupos). Mais além, traço fundamental, as relações que compõem a "estrutura social" são concebidas em termos de posições ("repartiam-se", "situados", "ordenarem-se") relativas ("sujeição próxima ou comando imediato", "uns acima dos outros").

Na conferência sobre as técnicas, em 1942, uma expressão ajuda a trazer mais precisão, acercando-nos do campo aproximado que a noção de "estrutura social" recobre em La société féodale. Bloch fala então na necessidade de se considerar a "estrutura interna da sociedade e a ação recíproca dos diversos grupos que a compõem". ${ }^{100}$ Por um lado, ao falar em "ação recíproca", Bloch põe novamente em questão o caráter relativo das posições sociais ("grupos", no caso). Com essa expressão, associada ao que denomina "estrutura interna" da sociedade, Bloch chama atenção para as relações internas, para a complexa inter-relação entre os diversos vínculos que compõem a estrutura social. No caso de La sociétéféodale, esse interesse, conforme vimos, se expressa na preocupação em explorar as relações que vínculos de parentesco, senhoriais, ou mesmo espirituais tiveram com o vínculo feudo-vassálico, centro de gravidade na "estrutura social" da "sociedade feudal", no entender de Bloch. Por outro lado, a expressão "ação recíproca" põe em evidência o agenciamento, a "ação", questão que remete a todo o problema do sujeito como agenciador da estrutura, como tentamos demonstrar no item anterior. Mais ainda, ao falar em "ação", percebe-se que a "estrutura social" se define e se compõe por meio de relações concretas, vínculos específicos, como o feudo-vassálico em La société féodale. $\mathrm{Na}$ Apologie, Marc Bloch prefere falar no plural "homens" ao invés do singular "homem" para delimitar o objeto do historiador, pois o singular é "favorável à abstração" ${ }^{101}$ e é para enfatizar a concretude dos "homens" que forja a bela metáfora do ogro-historiador, que, "onde fareja carne humana, sabe que ali está a sua caça". ${ }^{102}$ No caso da sociedade feudal, isso está lapidarmente resumido na afirmação de que "esta sociedade nada tinha de teorema". ${ }^{103}$

Com essa concepção da estrutura social, Bloch distingue-se novamente das posições durkheimianas. De fato, Durkheim concebia as sociedades como "conjuntos unificados" em que "conflito e divisão interna de interesse

\footnotetext{
${ }^{100}$ Marc Bloch, “As transformações das técnicas...”, op. cit., p. 178.

${ }^{101}$ Marc Bloch, Apologia da história, op. cit., p. 54.

${ }^{102}$ Idem, ibidem.

${ }^{103}$ Marc Bloch, La société féodale, vol. 2, p. 88.
} 
entre grupos são tratados apenas como um fenômeno de fases de transição no desenvolvimento social". ${ }^{104}$ Ora, se, como Peter Burke bem lembrou, Marc Bloch "compartilhava o interesse de Durkheim pela coesão social", ${ }^{105}$ essa era entendida por Bloch como resultante de um processo de correlações complexas, envolvendo grupos e indivíduos que, nas relações sociais concretas, delimitavam-se posições relativas uns aos outros. Por sua vez, essas relações, como aparecem em La société féodale, ordenavam-se entre si, formando um conjunto de relações interligadas. É a esse complexo de relações que remete a noção de "estrutura social". A ênfase recai nos processos de coerção mútua constitutivos da estrutura social, por contraponto à coesão de um todo pouco diferenciado. É, para lembrar expressão que já examinamos, no "jogo das instâncias" que reside o "remédio contra o fracionamento". ${ }^{106}$ Podemos, assim, precisar a definição que demos mais atrás do objeto da obra, entendendo a "estrutura social" como um conjunto de relações concretas ("laços", "vínculos”) que envolvem indivíduos e grupos ("homens"), em um processo ativo ("ação recíproca”) de complexa inter-relação ("estrutura interna”).

A "estrutura social" é, assim, mais que um conjunto de posições sociais; ela é um emaranhado de diversas relações e, ao concebê-las desse modo, Bloch se distingue da tradição sócio-estruturalista, que "percebe uma sociedade como um sistema de posições sociais" ${ }^{107}$ Segundo a perspectiva que abraça, o movimento ganha primazia com relação à posição, pois é a perpétua interação entre as diferentes instâncias de uma sociedade e entre os diversos grupos e indivíduos em uma estrutura social, que conferem existência a essa própria estrutura. Já em 1931, aliás, em artigo bibliográfico anteriormente aludido, Bloch nega qualquer tipo de reificação da noção de classe: "O erro de muitos historiadores consistiu, ao que parece, em atribuir às classes uma espécie de existência em si”. ${ }^{108}$

Essa percepção da "estrutura social”, não como um conjunto de posições bem definidas e estabilizadas, mas como relações (e relações entre relações) em perpétuo movimento, está articulada a um dado fundamental de seu pensamento - a relação entre subjetivismo e objetivismo, ou, mais especifi-

\footnotetext{
${ }^{104}$ Anthony Giddens, Durkheim, Londres, Fontana Press, 1978, p. 106.

${ }^{105}$ Peter Burke, História e teoria social, op. cit., p. 31.

${ }^{106}$ Marc Bloch, La société féodale, op. cit., vol. 2, p. 140.

${ }^{107}$ Victor Turner, The ritual process: structure and anti-structure [1969], Nova Iorque, Aldine de Gruyter, 1995, p. 131.

${ }^{108}$ Marc Bloch, “Féodalité, vassalité, seigneurie”, op. cit., p. 253.
} 
camente, entre idealismo e materialismo, como modalidades de explicação da sociedade. É conhecida a afirmação de Bloch de que "os fatos históricos são, por essência, fatos psicológicos", afirmação que frequentemente é associada a uma pretensa posição idealista de Bloch. ${ }^{109}$ Entretanto, um exame de sua obra mostra uma oscilação entre posições que tomam como ponto de partida a ação do subjetivo (por exemplo, o social como mentalidade coletiva) sobre o objetivo (por exemplo, o social como institucionalidade) e posições que tratam da ação do objetivo sobre o subjetivo, oposição bem condensada nas duas referências que Bloch faz ao medo do Inferno, em dois momentos distintos de La société féodale, e que levantam, pela contraposição, a seguinte pergunta: foi o medo do Inferno que gerou determinadas formas sociais ${ }^{110}$ ou foram determinadas formas sociais que geraram o medo do Inferno? ${ }^{111}$

É a esse problema capital, prenunciando a frase famosa da Apologie, que Bloch se referiu, no discurso em homenagem ao centenário de nascimento de Fustel de Coulanges, em 1930:

Ninguém melhor que Fustel soube que a história, antes de tudo, é psicologia. A força da autoridade imperial na Gália, a realeza franca, suas fraquezas, suas transformações, o laço vassálico e feudal - todas criações de uma certa mentalidade, de certos desejos, de certas paixões. ${ }^{112}$

De fato, Fustel afirmou de forma cristalina, em seu clássico A cidade antiga, sua concepção das relações entre o subjetivo e o objetivo como uma sucessão causal do primeiro ao segundo: "Fizemos a história de uma crença. Estabelece-se a crença: constitui-se a sociedade humana. Modifica-se a crença: a sociedade atravessa uma série de revoluções. A crença desaparece: a sociedade muda de aspecto". ${ }^{113}$ É famosa a crítica que Durkheim, com toda sua admiração a Fustel, expressou quanto a essa perspectiva: "ele [Fustel de Coulanges] tomou a causa pelo efeito. Depois de ter colocado a ideia religiosa sem fazê-la derivar de nada, dela deduziu os arranjos sociais que observava, quando, ao contrário, são estes últimos que explicam a força e a natureza da

\footnotetext{
${ }^{109}$ Marc Bloch, Apologia da história, op. cit., p. 157.

${ }^{110}$ Marc Bloch, La société féodale, vol. 1, p. 139.

${ }^{111}$ Idem, ibidem, vol. 2, p. 103.

${ }^{112}$ Marc Bloch, “Fustel de Coulanges...”, op. cit., p. 172.

${ }^{113}$ Numa Denis Fustel de Coulanges, A cidade antiga [1864], São Paulo, Martins Fontes, 1998, p. $450-451$.
} 
ideia religiosa". ${ }^{114}$ Durkheim, por assim dizer, inverte Fustel e propõe, em contraposição ao subjetivismo daquele, uma abordagem estritamente objetivista, em que as ideias seriam o fruto do mundo social (entendido como objetividade, como coisa, na terminologia durkheimiana), não suas causas.

Como vimos, Bloch se distinguiu em muitos pontos de Durkheim, e suas afirmações laudatórias de Fustel, especialmente no que tange à noção de que a história é psicologia, poderiam levar a pensar que, também em oposição a Durkheim, Bloch deve ser entendido como um advogado do subjetivismo como modalidade explicativa na história. Entretanto, como lembra salutarmente François Hartog, Bloch segue de perto a afirmação sobre a psicologia de uma afirmação sobre a centralidade da sociologia em Fustel (cf. supra, nota 18). Segundo Hartog,

o discurso sobre Fustel [...] mostra como ele [Bloch] as liga [suas preocupações] a Fustel, ou como ele lê em Fustel suas próprias preocupações; na medida em que ele reúne em um único olhar (psicologia + sociologia) o que, em Fustel, se sucedia (psicologia a princípio, depois preocupação com o social, a passagem se operando pelo uso da metáfora da alma e do corpo). ${ }^{115}$

De fato, é na distinção temporal entre ordens de fenômenos que se ligam por uma explicação causal - a ideia de origem - que se concentram as críticas de Bloch a Fustel, como se lê nos Caractères originaux, de $1931^{116} \mathrm{e}$, mais explicitamente, na Apologie:

[...] ao proceder mecanicamente, de trás para frente, corre-se sempre o risco de perder tempo na busca das origens ou das causas de fenômenos que, à luz da experiência, irão revelar-se, talvez, imaginários. [...] Fustel de Coulanges debruçou-se sobre as "origens" de instituições feudais das quais não formava, receio, senão uma imagem confusíssima... ${ }^{117}$

Essas críticas são reveladoras, assim, a respeito da noção de causalidade para Bloch, que só se poderia configurar como uma multicausalidade, e não como preeminência do subjetivo sobre o objetivo (como em Fustel) ou como

\footnotetext{
${ }_{114}$ Émile Durkheim, Da divisão do trabalho social [1893], trad., São Paulo, Martins Fontes, 1999, p. 162.

${ }^{115}$ François Hartog, Le XIXe siècle et l'histoire: le cas Fustel de Coulanges, Paris, Seuil, 2001, p. 213, nota 113.

${ }^{116}$ Marc Bloch, Les caractères originaux, op. cit., p. 49.

${ }^{117}$ Marc Bloch, Apologia da história, op. cit., p. 67.
} 
preeminência do objetivo sobre o subjetivo (como em Durkheim), conforme o autor declara explicitamente em La société féodale:

Será necessário acrescentá-lo? Ao inscrevermos esta exposição quase no início do livro, não pensamos absolutamente em postular, a favor das ordens de fatos que aqui serão retraçados sucintamente, qualquer primazia ilusória. [...] Nada seria mais vazio de sentido do que a dicotomia de pôr frente a frente, ao longo de uma evolução várias vezes secular, duas cadeias de fenômenos, por natureza dessemelhantes, e depois dizer: "eis deste lado as causas; do outro, eis todos os efeitos". Uma sociedade, tal como um espírito, não é toda tecida de perpétuas interações? ${ }^{\text {?11 }}$

Essas perpétuas interações, que presidem, portanto, à noção que Bloch faz de uma sociedade (a totalidade histórica) e impedem de classificá-lo como idealista ou materialista, são as mesmas que definem para ele a "estrutura social" como um conjunto ativo, mutável e inter-relacionado de vínculos concretos, em que a fixidez e a abstração da posição social cedem lugar ao movimento e à concretude da relação social.

É o que fica claro na resenha que Marc Bloch redigiu em 1937 sobre o livro Étude sur les tributaires d'Église dans le comté de Flandre du IXe au XVe siècle, de autoria de P. C. Boeren. Bloch critica o autor nos seguintes termos: "na estrutura social, ele não sente uma realidade essencialmente em movimento". ${ }^{119}$ Ao final da resenha, Bloch propõe um conjunto de perguntas que nos mostram o tipo de movimento, complexo e multidirecional, que Bloch julgava característico da estrutura social:

O essencial, para o historiador, é preservar o contato com os diversos elementos do concreto: a tradição que tendia a fixar ao indivíduo sua posição na sociedade e a lhe impor certos deveres; as pressões humanas que, em sentidos diversos, tendiam a modificar esse estatuto; os problemas novos, incessantemente levantados pelas circunstâncias e resolvidos tanto bem quanto mal segundo o costume ou segundo a balança de forças, em determinado momento. ${ }^{120}$

Reaparece aí a noção de concretude, articulada aos movimentos opostos da tradição e das pressões humanas, cuja correlação é vista em função de

\footnotetext{
${ }^{118}$ Marc Bloch, La société féodale, vol. 1, p. 95-96.

${ }^{119}$ Marc Bloch, “A propos d’une étude sur les liens seigneuriaux en Flandre: problèmes de méthode”, Annales d'histoire économique et sociale, 1937, p. 303.

${ }^{120}$ Idem, ibidem, p. 304.
} 
tendências, de um jogo de forças, e não como uma abstração identificável com posições sociais fixas. Em termos modernos, a "estrutura social” de Bloch, mais que a estrutura pronta, que, para ele, é uma abstração sem sentido, evoca, assim, o processo de "estruturação" da sociedade, para utilizarmos uma expressão cara a alguns autores vinculados ao chamado construcionismo social, especialmente teorizada por Anthony Giddens. ${ }^{121}$ Para Bloch, a estrutura só existe na condição de movimento, com seus polos gravitacionais, certamente, mas sem que a direção do movimento geral jamais implique chegada ou paralisia. ${ }^{122}$

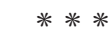

Em meio à pluralidade das instâncias de uma sociedade, Marc Bloch define e persegue um princípio unificador, um vínculo específico cujas características e vicissitudes assumem caráter estruturante para o conjunto daquela sociedade, fornecendo-lhe um polo gravitacional que tende a fazer com que as outras relações orbitem à sua volta. $\mathrm{O}$ resultado desse construto, a obra-mestra La société féodale, percebida por muitos também sob o signo de um plural fragmentário, reencontra sua unidade de concepção na forma peculiar como Bloch trata aquele vínculo, decorrente da concepção complexa que o autor tem da realidade social. Nesse sentido, a caracterização lapidar que Bloch atribui a seu objeto, "sociedade fragmentada e fundamentalmente una”, reverte-se em epígrafe de seu próprio trabalho.

\footnotetext{
${ }^{121}$ Anthony Giddens, A constituição da sociedade [1984], trad., São Paulo, Martins Fontes, 2003.

${ }^{122}$ Esse tipo de encaminhamento, é certo, Bloch não o "colheu” de suas leituras sociológicas - certamente, não de Durkheim. Porém, o senso de movência, de plasticidade e de concretude que se reflete em sua noção da estrutura social não é tampouco alheio às suas leituras: ele os colheu seletivamente - e os processou - a muitos autores, a Michelet, em primeiro lugar, em quem destaca a noção de "movimento vital" (Marc Bloch, Apologia da história, op. cit., p. 134), a Bergson, a quem associa a "plasticidade" que a história deve ter para "adaptar [...] suas classificações às "próprias linhas do real"” (idem, ibidem, p. 153), dentre outros.
} 